\title{
Electrically Controlled Nanofluidic DNA Sluice for Data Storage
}

\section{Applications}

Nagendra Athreya ${ }^{1,2}$, Apratim Khandelwal ${ }^{1,2}$, Xiuling Li $^{1,2}$, and Jean-Pierre Leburton ${ }^{1,2,3, *}$

${ }^{1}$ Department of Electrical and Computer Engineering, ${ }^{2}$ Holonyak Micro and Nanotechnology Laboratory, and ${ }^{3}$ Department of Physics, University of Illinois at UrbanaChampaign, Urbana, IL 61801

\section{Supporting Information}
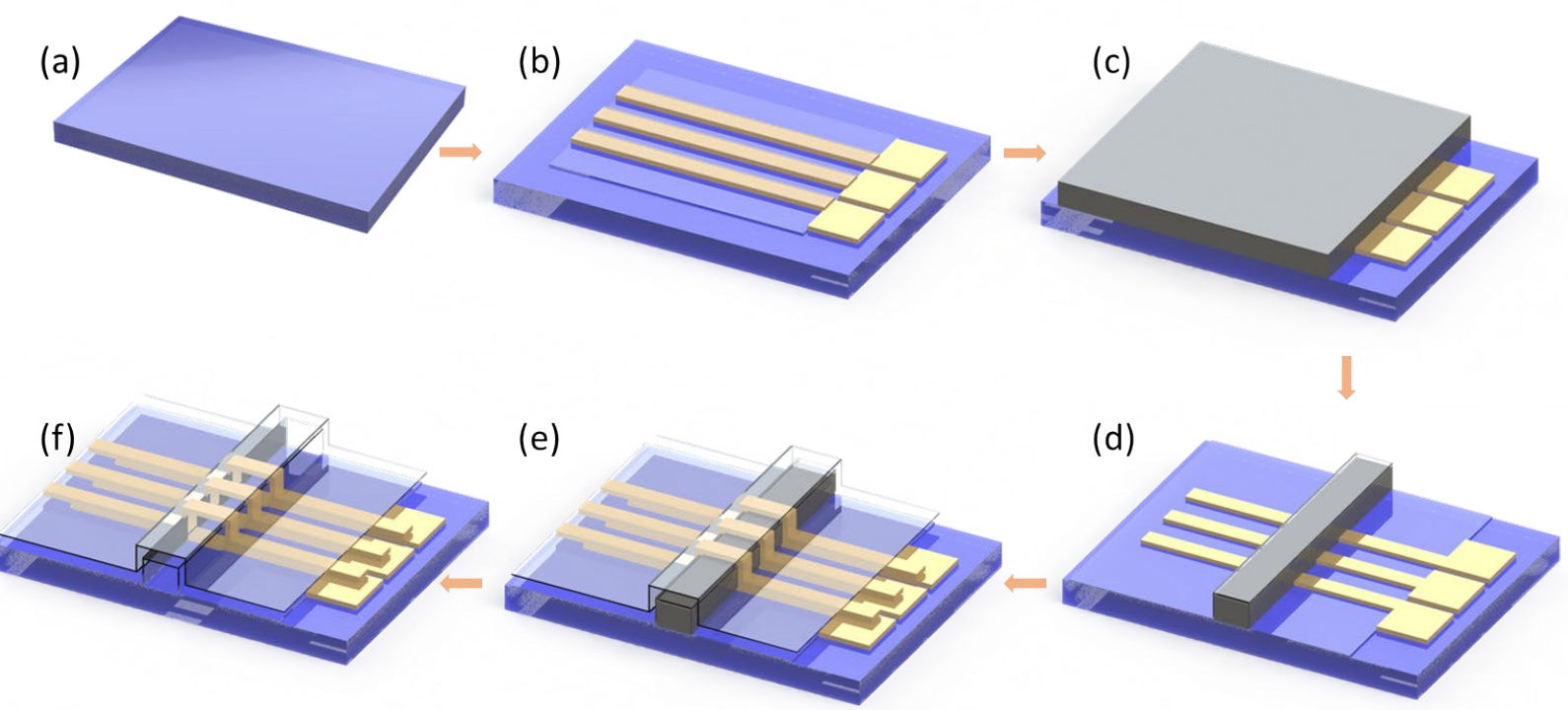

Figure S1. Anticipated key steps in the fabrication of DNA nano-tunnel device with buried arch electrodes. (a) Starting with clean and transparent bio-compatible substrate like sapphire that can ease DNA imaging; (b) Patterning buried $\mathrm{Au}$ electrodes and passivating them with $5 \mathrm{~nm}$ ALD alumina; (c) E-beam evaporate $100 \mathrm{~nm}$ Ge blanket; (d) Pattern the Ge into $3 \mu \mathrm{m} / 5 \mu \mathrm{m} / 10 \mu \mathrm{m}$ wide block. This Ge block is then passivated with 10 $\mathrm{nm}$ ALD alumina which acts as supporting roof of tunnel; (e) Top $\mathrm{Au}$ electrodes are then patterned as before and are then passivated with $5 \mathrm{~nm}$ ALD alumina; (f) Finally, the side etch windows are opened and Ge block is sacrificially etched to open the structure and create a $100 \mathrm{~nm}$ high tunnel like structure. 